\title{
Preoperative opioid consumption increases morphine requirement after leg amputation
}

\section{La consommation préopératoire d'opiacés augmente les doses requises de morphine après amputation de la jambe}

\author{
Stéphanie Roullet, MD · Karine Nouette-Gaulain, MD, PhD • Matthieu Biais, MD • \\ Nathalie Bernard, MD · Antoine Bénard, MD · Philippe Revel, MD • \\ Xavier Capdevila, MD, PhD · François Sztark, MD, PhD
}

Received: 28 February 2009/Accepted: 26 August 2009/Published online: 12 November 2009

(C) Canadian Anesthesiologists' Society 2009

\begin{abstract}
Purpose The aim of this observational study was to assess the influence of preoperative opioid consumption on postoperative morphine consumption after leg amputation performed under combined regional and general anesthesia.

Methods After Institutional Review Board approval, patients scheduled for leg amputation were included in a prospective observational study. A popliteal sciatic nerve catheter was placed preoperatively and $0.75 \%$ ropivacaine $20 \mathrm{~mL}$ was injected incrementally. Amputation was performed under general anesthesia. Postoperative analgesia included acetaminophen, a continuous infusion of $0.2 \%$ ropivacaine at $7 \mathrm{~mL} \cdot \mathrm{hr}^{-1}$, and intravenous morphine if the visual analogue scale (VAS) pain score was $>3$ on a 0-10 scale. Patients were divided post-hoc into two groups according to their preoperative opioid consumption: yes (Preop opioids) or no (No preop opioid).
\end{abstract}

This article is accompanied by an editorial. Please see Can J Anesth 56:12.

S. Roullet, $\mathrm{MD} \cdot \mathrm{K}$. Nouette-Gaulain, $\mathrm{MD}, \mathrm{PhD}$.

M. Biais, MD - P. Revel, MD - F. Sztark, MD, PhD ( $\bowtie)$

Service d'Anesthésie-Réanimation 1, Centre Hospitalo-

Universitaire de Bordeaux, 33076 Bordeaux Cedex, France

e-mail: francois.sztark@chu-bordeaux.fr

N. Bernard, MD $\cdot$ X. Capdevila, MD, PhD

Département d'Anesthésie Réanimation A, Hôpital Lapeyronie,

Montpellier, France

A. Bénard, MD

Institut de Santé Publique et d'Epidémiologie, Université Victor

Segalen Bordeaux 2, Bordeaux, France
Results Twenty-two patients were included, 12 in the Preop opioids Group and 10 in the No preop opioid Group. The VAS score after catheter insertion and before induction of general anesthesia was zero in both groups. Total postoperative opioid consumption from day 1 to day 3 and daily consumption at day 7 was greater in the Preop opioids Group than in the No preop opioid Group (52 [13-133] mg morphine equivalents vs 0 [0-26] $\mathrm{mg} ; P=0.02)$ and (10 [8-25] $\mathrm{mg}$ vs 0 [0-0] $\mathrm{mg} ; \mathrm{P}=0.01$ ), respectively, (median [25-75 interquartile values]).

Conclusion Despite the use of regional anesthesia, chronic opioid consumption before leg amputation is associated with increased postoperative morphine consumption and phantom limb pain.

\section{Résumé}

Objectif Le but de cette étude observationnelle était d'évaluer l'influence de la consommation chronique préopératoire d'opiacés sur la consommation postopératoire de morphine après amputation de la jambe réalisée sous anesthésie locorégionale et générale combinée.

Méthode Après accord du comité d'éthique local, des patients devant bénéficier d'une amputation de jambe ont été inclus prospectivement. Un cathéter sciatique poplité était mis en place en préopératoire et de la ropivacaïne 0,75 $\% 20$ mL était injecté en doses fractionnées. L'amputation était réalisée sous anesthésie générale. L'analgésie postopératoire comportait de l'acétaminophène, une perfusion continue de ropivacaïne $0,2 \%$ à $7 \mathrm{~mL} \cdot \mathrm{hr}^{-1}$ et de la morphine intraveineuse si le score sur une échelle visuelle analogique de 0 à 10 (EVA) était $>3$. Les patients ont été divisés a posteriori en deux groupes selon qu'ils étaient 
traités (groupe Preop opioids) ou non (groupe No preop opioid) par des opiacés en préopératoire.

Résultats Vingt-deux patients ont été inclus : 12 dans le groupe Preop opioids et 10 dans le groupe No Preop opioid. Le score EVA après l'insertion du cathéter et avant l'induction de l'anesthésie générale était égal à 0 dans les deux groupes. La consommation totale postopératoire

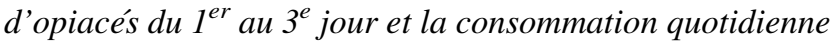
au $7^{e}$ jour étaient significativement plus importantes dans le groupe Preop opioids : 52 [13-133] mg équivalents de morphine vs 0 [0-26] $\mathrm{mg}(P=0,02)$ et 10 [8-25] $\mathrm{mg}$ vs 0 [0-0] $\mathrm{mg} \quad(P=0,01)$ respectivement (médiane [interquartile 25-75]).

Conclusion La consommation chronique d'opiacés avant amputation de la jambe est associée à une augmentation de la consommation postopératoire de morphine et de la douleur de membre fantôme malgré une technique d'anesthésie locorégionale.

Leg amputation induces complex postoperative pain and neuropathic symptoms such as phantom limb pain. Morphine remains the preferred analgesic for postoperative pain despite adverse effects, such as nausea, vomiting, drowsiness, respiratory depression, and opioid tolerance. In contrast, regional analgesia decreases morphine consumption and adverse effects. In cases of lower limb amputation, an epidural or peripheral nerve catheter inserted into the nerve sheath by the surgeon may reduce postoperative pain and morphine consumption. ${ }^{1-3}$ Furthermore, as continuous popliteal sciatic block is effective for postoperative pain management after leg, ankle, or foot surgery, ${ }^{4}$ this technique may be indicated in the perioperative management of amputation pain.

Post-amputation pain consists of stump pain and phantom limb pain. The pathophysiology of phantom limb pain is complex. ${ }^{5}$ Pre-amputation pain may occur in patients with or without morphine treatment. ${ }^{6-8}$ After leg amputation, stump pain is associated with phantom limb pain in $50-80 \%$ of amputees. ${ }^{5}$ Pre-amputation leg pain, ${ }^{7,8}$ like preoperative opioid dependence, ${ }^{9}$ is an important risk factor for postoperative pain and morphine consumption. However, no study has evaluated the role of chronic preoperative opioid use on post-amputation pain.

We conducted a prospective study in consecutive patients with peripheral arterial disease scheduled for lower limb amputation. Postoperative balanced analgesia, including continuous popliteal sciatic nerve analgesia with ropivacaine, was used in all patients. The patients were allocated into two groups according to their preoperative opioid consumption. Postoperative morphine consumption and the intensities of postoperative stump pain and phantom limb pain were compared.

\section{Methods}

This observational study was approved by our Institutional Review Board. Informed consent was obtained from patients older than $18 \mathrm{yr}$ with peripheral arterial disease who were scheduled for below-knee amputation under general anesthesia during the 18-month inclusion period. Exclusion criteria included post-traumatic or post-infectious amputation; pre-existing sciatica; infection at the sciatic catheter insertion point; coagulation disorder; local anesthetic, morphine, or acetaminophen allergy; and inclusion in another research protocol.

On the day before surgery, daily morphine or fentanyl consumption was recorded as an average per day over the last 2 weeks before amputation, regardless of the reason for analgesic consumption. Opioid consumption was expressed as intravenous (iv) morphine equivalents according to the following potency conversion: transdermic fentanyl $25 \mu \mathrm{g} \cdot \mathrm{hr}^{-1}=$ morphine $60 \mathrm{mg}$ po $=$ morphine $20 \mathrm{mg} i v$. Leg pain intensity at rest was evaluated using a visual analogue scale (VAS) ranging from $0 \mathrm{~cm}$ for no pain to $10 \mathrm{~cm}$ for the worst imaginable pain.

On the day of amputation, an $i v$ cannula was inserted, and patients were monitored with a non-invasive blood pressure device, electrocardiogram, and pulse oximeter. A few hours before general anesthesia, a sciatic nerve catheter was placed in the popliteal fossa. ${ }^{10} \mathrm{~A}$ stimulating catheter (Stimulong $^{\circledR}$, Pajunk ${ }^{\circledR}$, Geisingen, Germany) was inserted under sterile conditions using a nerve stimulator. A bolus of $0.75 \%$ ropivacaine $20 \mathrm{~mL}$ was injected and a disposable pump (Infusor $\mathrm{LV7}^{\circledR}$, Baxter S.A.S., Maurepas, France) with $0.2 \%$ ropivacaine was connected to the catheter. The saphenous nerve was not blocked. During the procedure, we noted the time for catheter insertion, the number of attempts, and adverse events: paraesthesiae, vascular puncture, tachycardia, cardiac arrhythmia, pain on injection, and seizures. Sciatic nerve block was considered successful when response to pinprick in the sciatic nerve territory was eliminated and when patients were unable to move their foot.

One hour before induction of general anesthesia, patients were premedicated orally with hydroxyzine $1 \mathrm{mg} \cdot \mathrm{kg}^{-1}$, and amoxicillin-clavulanic acid $2 \mathrm{~g}$ iv was administered. In case of penicillin allergy, patients received clindamycin $600 \mathrm{mg}$ and gentamycin $3 \mathrm{mg} \cdot \mathrm{kg}^{-1}$. After preoxygenation, general anesthesia was induced with sufentanil $0.5 \mu \mathrm{g} \cdot \mathrm{kg}^{-1}$, ketamine $0.15 \mathrm{mg} \cdot \mathrm{kg}^{-1}$, and propofol $2.5 \mathrm{mg} \cdot \mathrm{kg}^{-1}$ or etomidate $0.3 \mathrm{mg} \cdot \mathrm{kg}^{-1}$. Atracurium $0.5 \mathrm{mg} \cdot \mathrm{kg}^{-1}$ was administered to facilitate tracheal intubation, and neuromuscular block was monitored. After tracheal intubation, anesthesia was maintained with sevoflurane in oxygen/air without nitrous oxide. Sufentanil $0.1 \mu \mathrm{g} \cdot \mathrm{kg}^{-1}$ was administered if the patient's heart rate increased by more than $20 \%$ over the 
preoperative value (the day before amputation) for more than $60 \mathrm{sec}$. For patients who had a transdermic patch of fentanyl, the patch was left in place perioperatively.

Postoperatively, intravenous acetaminophen $1 \mathrm{~g}$ was given four times daily. A continuous infusion of $0.2 \%$ ropivacaine at $7 \mathrm{~mL} \cdot \mathrm{hr}^{-1}$ was started in the popliteal sciatic nerve catheter at the end of surgery. In the postanesthesia care unit, intravenous morphine $2 \mathrm{mg}$ every $5 \mathrm{~min}$ was administered until the VAS score was $<3$. On the surgical ward, patients used a patient-controlled analgesia (PCA) device for morphine $i v$ administration (bolus $1 \mathrm{mg}$, lock-out time $10 \mathrm{~min}$, no continuous infusion). If they could not use a PCA device, the patients received sub-cutaneous and oral morphine with an appropriate rescue analgesia protocol.

On the surgical ward, an anesthesiologist, who was aware of the protocol, visited each patient on days 1,2, and 3 and recorded the following: VAS score for stump pain and phantom limb pain, presence of phantom limb sensation, daily morphine consumption, plasma troponin level, electrocardiogram changes, seizures, nausea or vomiting, sedation, respiratory failure, urinary retention, and antiemetic consumption.

Phantom limb pain was defined as any painful sensation in the missing limb. The following sensations were sought: burning, painful cold, electric shocks, painful tingling, sensation of pins and needles, painful numbness, and itching. ${ }^{11}$ If a patient reported one or more of these painful sensations in the missing limb, he/she was considered as having phantom limb pain.

Popliteal sciatic catheters were removed on day 3. On day 7, an anesthesiologist visited the patients and the following parameters and events were noted: scores of stump pain and phantom limb pain, daily morphine consumption, troponin levels, new surgical amputation, cardiac events, local or general sepsis, and death. Patients were followed by surgeons and anesthesiologists, and cardiac events and death were recorded during the first year.

\section{Statistical analysis}

Patients were divided into two groups according to chronic preoperative opioid consumption during the 7 days prior to surgery. Patients taking morphine or fentanyl preoperatively were allocated to the Preop opioids Group, while patients with no opioid consumption were allocated to the No preop opioid Group. The primary endpoint was to assess the influence of chronic preoperative opioid consumption ( $>7$ days before surgery) on total postoperative morphine consumption until postoperative day 3 . The secondary endpoint was to assess the influence of preoperative opioid consumption on morphine consumption at postoperative day 7. Variables in both groups were compared with a MannWhitney test for quantitative data and with a Fisher exact test for qualitative data. Statistical analysis was performed with SAS ${ }^{\circledR}$ software (SAS Institute, Cary, NC, USA). Results are expressed as mean \pm SD or median (25-75 interquartile range). A $P$ value $<0.05$ was considered as indicating statistically significant differences.

\section{Results}

From July 2005 to November 2006, 30 patients were scheduled for leg amputation. Twenty-two patients agreed to participate and were included in the study: 12 patients in the Preop opioids Group and 10 patients in the No preop opioid Group. One patient from each group did not complete the trial until day 7. Patient characteristics are presented in Table 1. No significant difference was noted except for preoperative opioid consumption. Patients with preoperative opioids had been treated for at least 1 week with opioids before amputation. All patients received acetaminophen as analgesic treatment.

All continuous sciatic nerve blocks were successful. Mean time for catheter insertion was $15 \pm 8$ min and all catheters were inserted after one attempt. In the No preop opioid Group, there was one vascular puncture and one patient complained about pain during injection without any clinical complication. Before induction of general anesthesia, median VAS score was 0 in both groups.

Intraoperative consumption of sufentanil was significantly higher in the Preop opioids Group than in the No

Table 1 Patient characteristics

\begin{tabular}{lll}
\hline & \multicolumn{2}{l}{ Preoperative opioids } \\
\cline { 2 - 3 } & $\begin{array}{l}\text { No } \\
(n=10)\end{array}$ & $\begin{array}{l}\text { Yes } \\
(n=12)\end{array}$ \\
\hline Age $(\mathrm{yr})$ & $68 \pm 12$ & $70 \pm 10$ \\
Gender: male/female & $9 / 1$ & $10 / 2$ \\
Amputation level & & \\
Leg (below knee) & 7 & 10 \\
Transmetatarsus & 3 & 2 \\
BMI $\left(\mathrm{kg} \cdot \mathrm{m}^{-2}\right)$ & $22.2 \pm 4.5$ & $23.7 \pm 3.4$ \\
ASA class $2 / 3 / 4$ & $1 / 7 / 2$ & $2 / 10 / 0$ \\
Creatinine clearance $\left(\mathrm{mL} \cdot \mathrm{min}^{-1}\right)$ & $67 \pm 47$ & $66 \pm 40$ \\
Diabetes mellitus & 7 & 8 \\
Preoperative VAS score $\left(0-10\right.$ scale $\left.^{2}\right)$ & $2(0-4)$ & $7(4-8)$ \\
Daily morphine equivalent dose & $0(0-0)$ & $27(12-58)$ \\
$\quad\left(\mathrm{mg} \cdot\right.$ day $\left.^{-1}\right)$ & & \\
\hline
\end{tabular}

Patients were divided into two groups according to chronic preoperative opioid consumption. Data are expressed as mean $\pm \mathrm{SD}$, median (25-75 interquartile range) or number. Creatinine clearance was calculated by the Cockroft and Gault formula

ASA American Society of Anesthesiologists, BMI body mass index, $V A S$ visual analogue scale 


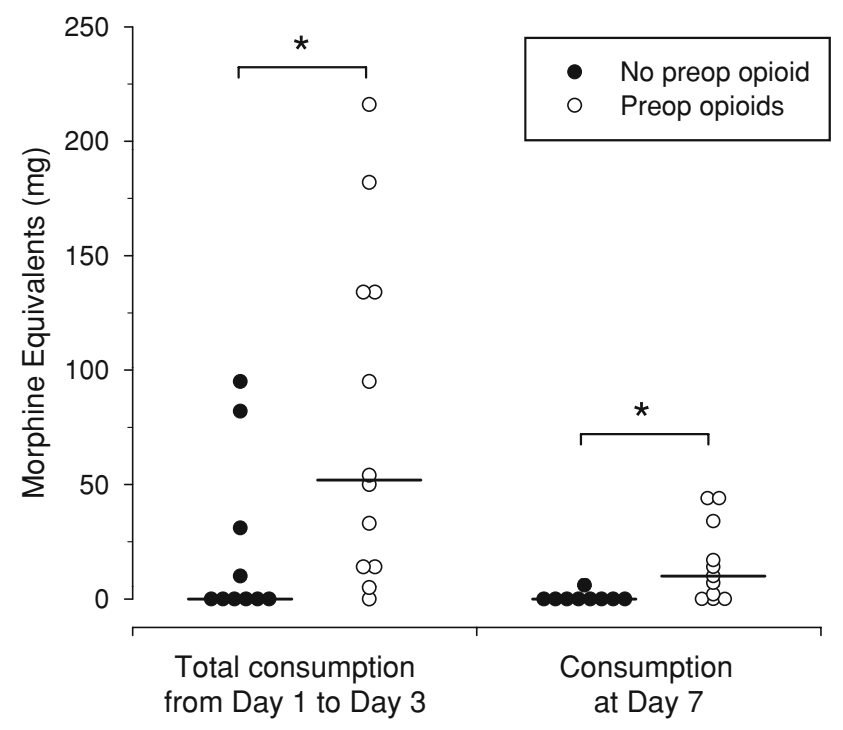

Fig. 1 Total postoperative consumption of morphine equivalents from day 1 to day 3 and daily consumption at day 7. Each point represents a patient. Plain circles $=$ no preoperative opioid; empty circles $=$ preoperative opioids. Horizontal bars represent median values. * $P<0.05$ between groups

preop opioid Group $(0.71 \pm 0.61$ vs $0.37 \pm 0.27 \mu \mathrm{g}$. $\left.\mathrm{kg}^{-1} \cdot \mathrm{hr}^{-1} ; P=0.03\right)$. The Preop opioids Group required more morphine equivalents from postoperative day 1 to day $3(52[13-133] \mathrm{mg})$ than the No preop opioid Group (0 [0-26] mg) $(P=0.02)$. Also, morphine equivalent consumption on day 7 was significantly greater in the Preop opioids Group than in the No preop opioid Group (10 [825] $\mathrm{mg}$ vs 0 [0-0] $\mathrm{mg} ; P=0.01)$. Individual data are shown in Fig. 1.

Incidence of phantom limb pain from day 1 to day 3 was not significantly different between groups: Preop opioids Group, $67 \%, 71 \%$, and $88 \%$ on day 1,2 , and 3 , respectively; No preop opioid Group, 33, 60, and 56\%, on day 1 , 2 , and 3, respectively (NS). The VAS score for stump pain was significantly greater in the Preop opioids Group on days 1 and 2 (Fig. 2). The VAS score for phantom limb pain was significantly greater in Preop opioids Group on day 7 (Fig. 3).

Popliteal sciatic nerve catheters were maintained $62 \pm 20 \mathrm{hr}$ in the No preop opioid Group and $56 \pm 23 \mathrm{hr}$ in the Preop opioids Group (NS). No local or systemic signs of clinical infection were noted.

On day 1 , one patient in the No preop opioid Group presented a respiratory depression with oxygen saturation $<92 \%$ treated by oxygen; another patient had acute urinary retention and another experienced vomiting. On days 2 and 3 , no complications were noted. On day 1 , one patient in each group presented an increase in troponin level without any electrocardiographic modification. Troponin levels were normal on days 2 and 3. No coronary cardiac event occurred during the 1-year survey period, even though one

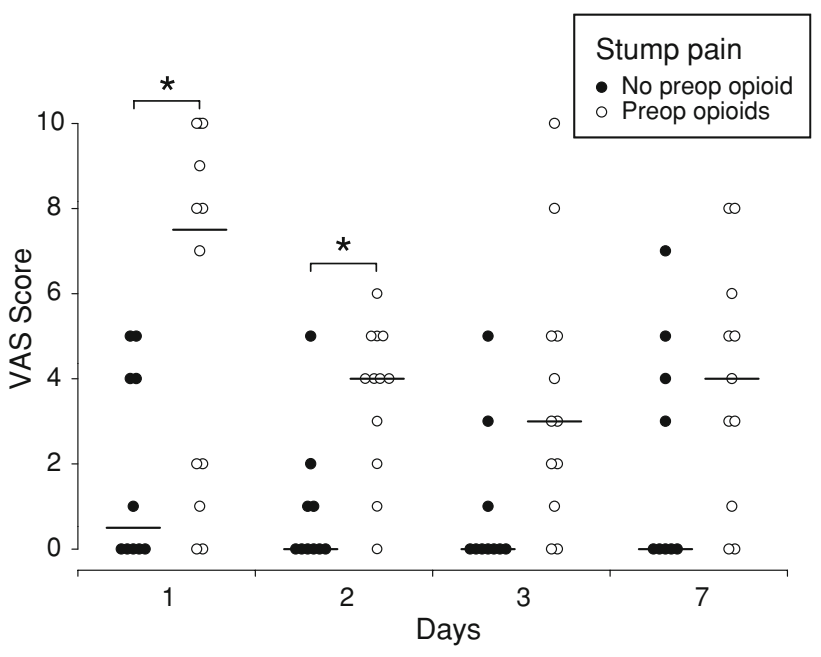

Fig. 2 Visual analogue scale (VAS) score for stump pain at days 1, 2, 3, and 7. Each point represents a patient. Plain circles $=$ no preoperative opioid; empty circles $=$ preoperative opioids. Horizontal bars represent median values. $* P<0.05$ between groups

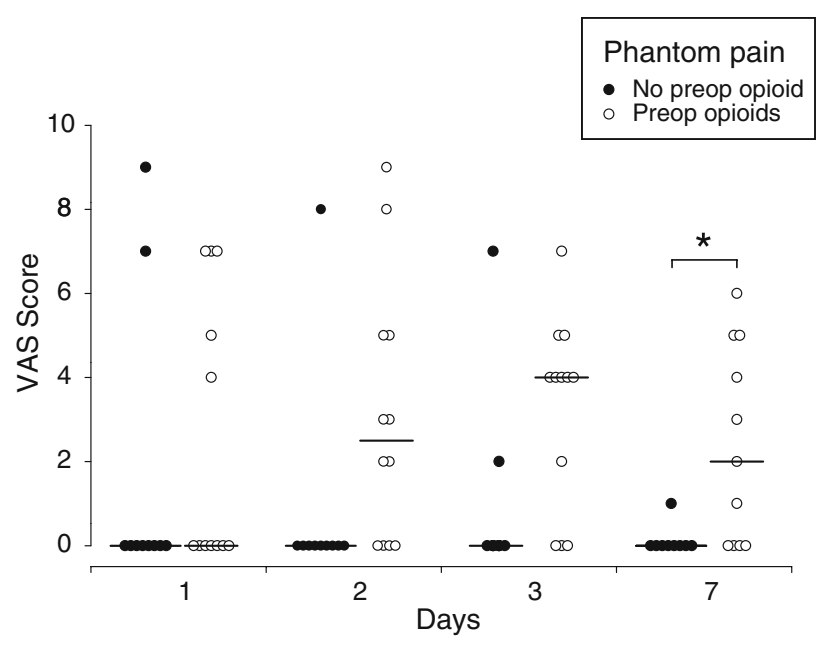

Fig. 3 Visual analogue scale (VAS) score for phantom limb pain at days 1, 2, 3, and 7. Each point represents a patient. Plain circles = no preoperative opioid; empty circles $=$ preoperative opioids. Horizontal bars represent median values. $* P<0.05$ between groups

patient presented a myocardial infarction less than 1 month before amputation. On day 7, one patient in the Preop opioids Group died because of cerebral ischemia. Three patients in the No preop opioid Group and one in the Preop opioids Group had a local infection at the stump wound. No patient needed a new surgical procedure.

\section{Discussion}

This study shows that postoperative morphine consumption is greater in patients with chronic preoperative opioid consumption despite effective analgesia with a continuous popliteal sciatic nerve block placed before limb amputation. 
Patients with peripheral vascular disease experience pain before surgery and consume analgesics chronically. Daily morphine consumption is often high, with a median of $27 \mathrm{mg}$ per day in our study, and $40 \mathrm{mg}$ per day in another study. ${ }^{7}$ In such patients, preoperative pain has been described as a risk factor for postoperative pain and phantom limb pain after leg amputation.,12 Epidural analgesia performed the day before surgery has been suggested to decrease pain before amputation. Nikolajsen et al. randomized patients into two groups: epidural bupivacaine and morphine group, or epidural saline and oral or intramuscular morphine group. ${ }^{7}$ The study started $18 \mathrm{hr}$ before surgery and treatment was continued for 6-day postoperatively. On day 7 , median daily morphine consumption was not significantly different between the groups, but all patients in that study took opioids chronically before the operation.

In our hospital, patients were transferred to the surgical ward the day before amputation, thus we could scarcely influence their preoperative analgesic treatment. Opioid treatment was not initiated systematically before surgery despite preoperative pain in many patients. We thus defined No preop opioid and Preop opioids groups according to preoperative opioids (morphine or fentanyl) consumption or not. Patients in the Preop opioids Group were on opioids for at least 1 week. We expressed opioid consumption as equivalent $i v$ morphine doses; however, equivalent potency conversion of opioids remains empirical and applies to patients on stable doses of opioids.

Patients with preoperative opioid treatment suffered from phantom limb pain at postoperative day 7 . Phantom limb pain is a neuropathic pain with a central element probably not fully prevented by regional analgesia in the preoperative period, ${ }^{7,13,14}$ whereas thoracic epidural analgesia decreases neuropathic pain until 6 months after thoracotomy. ${ }^{15-17}$ For leg amputation, regional anesthesia techniques, such as epidural anesthesia or peripheral nerve catheters, were not found efficacious in entirely preventing phantom limb pain or in decreasing postoperative morphine consumption on day 7 , or at 1 and 6 months. ${ }^{1,2,7,18-23}$ In these studies, patients experienced pain for days or months before amputation, and central sensitization and cortical plasticity, which had developed over a long period before amputation, were probably also involved. ${ }^{24,25}$ For these reasons, prolonged analgesia with ropivacaine in the vicinity of the sciatic nerve could not prevent chronic postoperative pain or phantom limb pain in the case of amputation. ${ }^{26} \mathrm{~A}$ major concern for medical staff is to treat preoperative pain adequately and to block central sensitization as much as possible. There could be an indication to perform regional analgesia several days before surgery. Unfortunately, for patients with peripheral vascular disease, the decision to amputate is not made in most cases until the day before or even the same day as the amputation. Therefore, a true pre-emptive treatment is difficult to initiate. $^{27}$ According to the theory of central sensitization and cortical plasticity, phantom limb pain is associated with chronic pre-amputation pain. ${ }^{24}$ Prevention of phantom limb pain would require effective preoperative analgesia to counteract central sensitization. Opioid treatment could itself lead to sensitization, ${ }^{28}$ and multimodal analgesia, including regional anesthesia, deserves to be investigated further. In our study, we used ketamine during general anesthesia in all patients. Ketamine at low dose acts as an antagonist of $N$-methyl-D-aspartate (NMDA) receptors with anti-hyperalgesic properties. $^{29}$ We did not use nitrous oxide, which also could have counteracted central sensitization. For elderly vascular patients scheduled for painful surgery, a regional analgesia technique with popliteal sciatic nerve catheter was performed systematically. After orthopedic surgery, continuous infusions of local anesthetics to block the sciatic nerve offer the benefits of prolonged analgesia with fewer side effects, greater patient satisfaction, and faster recovery than morphine. ${ }^{30-32}$

In our study, patients were elderly ( $>65 \mathrm{yr}$ old), 15 had diabetes mellitus, and 3 needed hemodialysis. They were at risk of postoperative coronary events ${ }^{27,33}$ or local complications after regional analgesia (nervous, muscular, septic). The cardiovascular complications noted in our study are similar to those reported by Subramaniam et al., who classified leg amputation as a surgical procedure with intermediate cardiovascular risk. ${ }^{33}$

There are some biases and limits in our study, for example, the lack of blinding. Most of the patients knew the amount of morphine they were taking before surgery, and the investigators were aware of this information. Some patients were deemed unfit for PCA, which probably influenced the postoperative morphine administered. This is one of the difficulties of studies that include elderly patients. In further studies, it would be an important point to define a single means of administering morphine for all patients.

In conclusion, after leg amputation in patients with sciatic nerve catheter, total postoperative morphine consumption until day 3 and daily morphine consumption on day 7 were significantly higher in patients with chronic preoperative opioid consumption. For patients with a history of morphine consumption, the analgesic protocol could probably be improved by initiating regional analgesia for a longer period before surgery, but further studies are warranted to confirm this hypothesis.

Acknowledgment The authors thank Ray Cooke for revising the English.

Funding The study was supported by institutional funding.

Conflicts of interest None declared. 


\section{References}

1. Bach $S$, Noreng $M F$, Tjellden NU. Phantom limb pain in amputees during the first 12 months following limb amputation, after preoperative lumbar epidural blockade. Pain 1988; 33: 297-301.

2. Fisher A, Meller Y. Continuous postoperative regional analgesia by nerve sheath block for amputation surgery-a pilot study. Anesth Analg 1991; 72: 300-3.

3. Ong BY, Arneja A, Ong $E W$. Effects of anesthesia on pain after lower-limb amputation. J Clin Anesth 2006; 18: 600-4.

4. Singelyn FJ, Aye F, Gouverneur JM. Continuous popliteal sciatic nerve block: an original technique to provide postoperative analgesia after foot surgery. Anesth Analg 1997; 84: 383-6.

5. Flor $H$. Phantom-limb pain: characteristics, causes, and treatment. Lancet Neurol 2002; 1: 182-9.

6. Nikolajsen L, Ilkjaer S, Kroner K, Christensen JH, Jensen TS. The influence of preamputation pain on postamputation stump and phantom pain. Pain 1997; 72: 393-405.

7. Nikolajsen L, Ilkjaer S, Christensen JH, Kroner K, Jensen TS. Randomised trial of epidural bupivacaine and morphine in prevention of stump and phantom pain in lower-limb amputation. Lancet 1997; 350: 1353-7.

8. Nikolajsen L, Jensen TS. Phantom limb pain. Br J Anaesth 2001; 87: 107-16.

9. Mehta V, Langford RM. Acute pain management for opioid dependent patients. Anaesthesia 2006; 61: 269-76.

10. March X, Pineda O, Garcia MM, Carames D, Villalonga A. The posterior approach to the sciatic nerve in the popliteal fossa: a comparison of single- versus double-injection technique. Anesth Analg 2006; 103: 1571-3.

11. Bouhassira D, Attal N, Alchaar H, et al. Comparison of pain syndromes associated with nervous or somatic lesions and development of a new neuropathic pain diagnostic questionnaire (DN4). Pain 2005; 114: 29-36.

12. Hanley MA, Jensen MP, Smith DG, Ehde DM, Edwards WT, Robinson LR. Preamputation pain and acute pain predict chronic pain after lower extremity amputation. J Pain 2007; 8: 102-9.

13. Lambert AW, Dashfield AK, Cosgrove C, Wilkins DC, Walker $A J$, Ashley $S$. Randomized prospective study comparing preoperative epidural and intraoperative perineural analgesia for the prevention of postoperative stump and phantom limb pain following major amputation. Reg Anesth Pain Med 2001; 26: 316-21.

14. Kehlet H, Jensen TS, Woolf CJ. Persistent postsurgical pain: risk factors and prevention. Lancet 2006; 367: 1618-25.

15. Gottschalk A, Cohen SP, Yang S, Ochroch A. Preventing and treating pain after thoracic surgery. Anesthesiology 2006; 104: 594-600.

16. Wu CL, Cohen SR, Richman JM, et al. Efficacy of postoperative patient-controlled and continuous infusion epidural analgesia versus intravenous patient-controlled analgesia with opioids: a meta-analysis. Anesthesiology 2005; 103: 1079-88.

17. Obata H, Saito S, Fujita N, Fuse Y, Ishizaki K, Goto F. Epidural block with mepivacaine before surgery reduces long-term postthoracotomy pain. Can J Anesth 1999; 46: 1127-32.
18. Malawer MM, Buch R, Khurana JS, Garvey T, Rice L. Postoperative infusional continuous regional analgesia. A technique for relief of postoperative pain following major extremity surgery. Clin Orthop Relat Res 1991; 266: 227-37.

19. Elizaga AM, Smith DG, Sharar SR, Edwards WT, Hansen ST Jr. Continuous regional analgesia by intraneural block: effect on postoperative opioid requirements and phantom limb pain following amputation. J Rehabil Res Dev 1994; 31: 179-87.

20. Jahangiri M, Jayatunga AP, Bradley JW, Dark CH. Prevention of phantom pain after major lower limb amputation by epidural infusion of diamorphine, clonidine and bupivacaine. Ann R Coll Surg Engl 1994; 76: 324-6.

21. Morey TE, Giannoni J, Duncan E, Scarborough MT, Enneking $F K$. Nerve sheath catheter analgesia after amputation. Clin Orthop Relat Res 2002; 397: 281-9.

22. Nikolajsen L, Ilkjaer S, Jensen T. Effect of preoperative extradural bupivacaine and morphine on stump sensation in lower limb amputees. Br J Anaesth 1998; 81: 348-54.

23. Pinzur M, Garla P, Pluth T, Vrbos L. Continuous postoperative infusion of a regional anesthetic after an amputation of the lower extremity. A randomized clinical trial. J Bone Joint Surg Am 1996; 78: 1501-5.

24. Flor H, Birbaumer $N$. Phantom limb pain: cortical plasticity and novel therapeutic approaches. Curr Opin Anaesthesiol 2000; 13: 561-4.

25. Flor H, Elbert T, Knecht $S$, et al. Phantom-limb pain as a perceptual correlate of cortical reorganization following arm amputation. Nature 1995; 375: 482-4.

26. Katz J. Prevention of phantom limb pain by regional anaesthesia. Lancet 1997; 349: 519-20.

27. Nikolajsen L, Finnerup NB, Kramp S, Vimtrup AS, Keller J, Jensen TS. A randomized study of the effects of gabapentin on postamputation pain. Anesthesiology 2006; 105: 1008-15.

28. Simonnet $G$, Rivat $C$. Opioid-induced hyperalgesia: abnormal or normal pain? NeuroReport 2003; 14: 1-7.

29. Richebe $P$, Rivat $C$, Rivalan B, Maurette $P$, Simonnet $G$. Low doses ketamine: antihyperalgesic drug, non-analgesic (French). Ann Fr Anesth Reanim 2005; 24: 1349-59.

30. Capdevila X, Barthelet $Y$, Biboulet P, Ryckwaert $Y$, Rubenovitch $J$, d'Athis $F$. Effects of perioperative analgesic technique on the surgical outcome and duration of rehabilitation after major knee surgery. Anesthesiology 1999; 91: 8-15.

31. Williams BA, Kentor ML, Vogt MT, et al. Reduction of verbal pain scores after anterior cruciate ligament reconstruction with 2-day continuous femoral nerve block: a randomized clinical trial. Anesthesiology 2006; 104: 315-27.

32. Salinas FV, Liu SS, Mulroy MF. The effect of single-injection femoral nerve block versus continuous femoral nerve block after total knee arthroplasty on hospital length of stay and long-term functional recovery within an established clinical pathway. Anesth Analg 2006; 102: 1234-9.

33. Subramaniam B, Pomposelli F, Talmor D, Park KW. Perioperative and long-term morbidity and mortality after above-knee and below-knee amputations in diabetics and nondiabetics. Anesth Analg 2005; 100: 1241-7. 